\title{
Reliability Analysis of Gas Pipeline with Corrosion Defects
}

\author{
Wang Lihang \\ School of Petroleum Engineering, Yangtze University, Wuhan 430100, China
}

\begin{abstract}
The parameters such as pipe diameter, pipe wall thickness and working pressure are all uncertain, so the X80 pipeline used in gas pipeline transportation is considered as an example. Based on the B31G standard, a reliability model is established for the pipeline containing corrosion defects. The results show that the reliability of the pipeline will be less than the target reliability, and the sensitivity analysis shows that the influence of working pressure on the reliability of the pipeline is not safe.
\end{abstract}

Key words: Gas pipeline, reliability, B31G principle, target reliability.

\section{Preface}

With the sustainable development of the national economy, the demand for natural gas is increasing. In west to east gas transmission line, second-line and other large-scale projects, gas transmission pipeline are mostly used buried. Because of the factors such as welding defects or corrosion and other factors, the pipeline installation and service process will cause the local stress concentration phenomenon, which will eventually lead to pipeline failure. The performance parameters and load parameters are uncertain, so it is necessary to introduce the reliability probability method to study the reliability of the pipeline [1]. In recent years, scholars at home and abroad through the reliability theory has done a lot of research on the pipeline, such as the influence of various factors Shuai Jian [2] pipe residual life as random variables with different distribution. A mathematical model for predicting the failure probability of pipeline is established as well as the effects of the corrosion rate, defect depth, pipe wall thickness and the work pressure and other factors on line reliability. Zhang G [3] introduce the reliability theory, using Monte Carlo simulation method of pipeline reliability with the

Corresponding author: Wang Lihang, master's degree, research fields: reliability and safety analysis of oil and gas pipeline. defect size changes, Ahammed [4] researched the reliability of localized corrosion of pipeline.

To solve a lot of defects in pipes evaluation methods, such as ASME B31G [5], DNV-F101 [6], API579 [7] etc., we use the latest version of the ASME B31G. The west to east gas transmission use the wide range of X80 pipeline of reliability assessment. The final analysis of the different parameters about the pipeline rely on the influence degree of sensitivity.

\section{Reliability Calculation of Gas Pipeline with Defects}

\subsection{Limit State Equation Based on PCORRC}

The reliability analysis of the pipeline containing defects is carried out by using the PCORRC criterion:

$$
Z=p_{f}-p_{o p}
$$

when $\mathrm{Z}>0$, the pipeline is in a safe state, when $\mathrm{Z}=0$, the pipeline is in the limit state and when $Z<0$, the pipeline is the failure state.

\subsection{Monte-Carlo Calculation Based on PCORRC}

Reliability, also known as reliability, is a measure of the ability of a product to perform a predetermined function at a specified time and condition. The core of 
the algorithm of reliability based design and evaluation method is the calculation of the limit state equation, which can be accomplished through a variety of methods. In order to avoid pipeline reliability analysis of mathematical difficulties, without taking into account the complexity of function, the Monte Carlo method of pipeline can be on line analysis. Monte Carlo method is a kind of calculation method based on random number, using the basic idea of the method: Have a group with a sample of random variable distribution according to the basic parameters of the pipeline by using Monte-Carlo method, into the limit state equation of $\mathrm{Z}$, can be calculated by a random number. Repeated simulation by this method, we get $\mathrm{N}$ random number, and finally the number of statistics is greater than zero for $\mathrm{M}$. When $\mathrm{N}$ tends to infinity, by the large number theorem, can be obtained for the reliability of $M / N$. For the specific operation, flow of gas pipeline is shown in Fig. 1. Because of the number of simulation, this paper realizes the calculation of reliability by using Matlab program.

\section{Example Calculation}

\subsection{Pipeline Parameters}

The basic parameters of the pipeline are shown in Tables 1 and 2 [8].

\subsection{Target Reliability}

In this paper, based on the analysis method of reliability theory, the west east gas pipeline is evaluated. To this end, the pipeline target reliability based on API579, which corresponds to a class of low risk, corresponding to the two types of regional risks, the corresponding high risk in the three or four categories (Table 3) [9]. The west to east gas transmission pipeline are mostly in the sparsely populated region for low risk area. Therefore, we take 0.99 for pipeline target reliability.

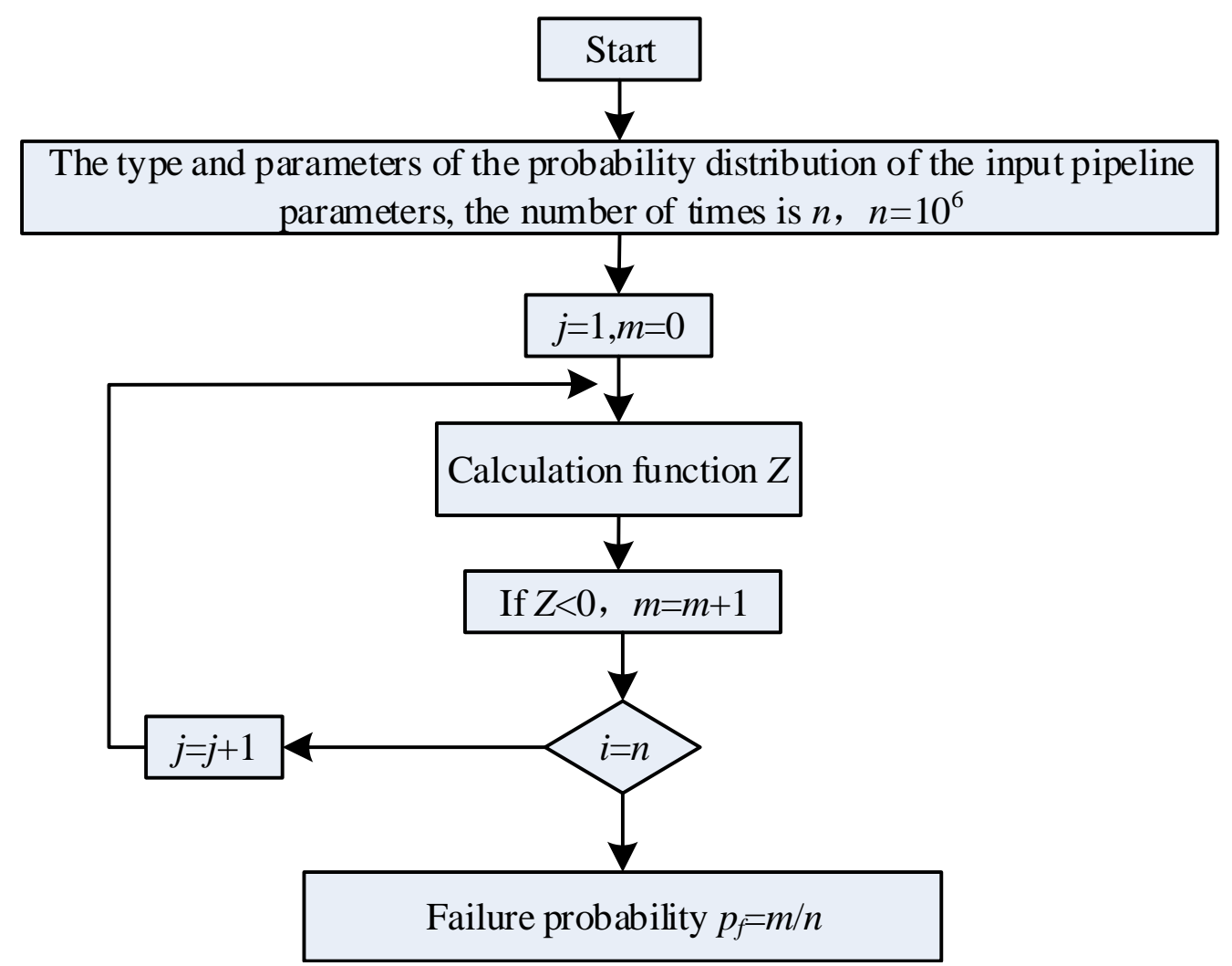

Fig. 1 Monte-Carlo method calculation flow chart. 
Table 1 Pipe size.

\begin{tabular}{llllll}
\hline Steel grade & Specifications & $\begin{array}{l}\text { Mean diameter of } \\
\text { pipe diameter } / \mathrm{mm}\end{array}$ & $\begin{array}{l}\text { Standard deviation of pipe } \\
\text { diameter } / \mathrm{mm}\end{array}$ & $\begin{array}{l}\text { Mean value of wall } \\
\text { thickness } / \mathrm{mm}\end{array}$ & $\begin{array}{l}\text { Standard deviation of } \\
\text { wall thickness } / \mathrm{mm}\end{array}$ \\
\hline X80 & $\phi 1219 \times 18.4$ & 1219 & 1.33 & 18.86 & 0.46 \\
\hline
\end{tabular}

Table 2 Pipeline operating pressure.

\begin{tabular}{lllll}
\hline Steel grade & Specifications & Design pressure/MPa & $\begin{array}{l}\text { Mean value of } \\
\text { pressure/MPa }\end{array}$ & $\begin{array}{l}\text { Standard deviation of } \\
\text { pressure/MPa }\end{array}$ \\
\hline X80 & $\phi 1219 \times 18.4$ & 12 & 9.16 & 0.916 \\
\hline
\end{tabular}

Table 3 Target reliability.

\begin{tabular}{|c|c|c|c|c|c|}
\hline \multirow{2}{*}{$\begin{array}{l}\text { Propose organizations } \\
\text { and institutions }\end{array}$} & \multicolumn{3}{|c|}{ Target reliability (maximum failure probability) } & \multirow{2}{*}{$\begin{array}{l}\text { Reliability analysis } \\
\text { method }\end{array}$} & \multirow{2}{*}{ Scope of application } \\
\hline & Low risk & Mid risk & High risk & & \\
\hline API (API579) & $0.99\left(10^{-2}\right)$ & $0.999\left(10^{-3}\right)$ & $0.99999\left(10^{-5}\right)$ & $\begin{array}{l}\text { Based on reliability } \\
\text { theory }\end{array}$ & $\begin{array}{l}\text { Oil and gas pipelines, } \\
\text { pressure vessels and } \\
\text { refining equipment }\end{array}$ \\
\hline
\end{tabular}

Table 4 Reliability calculation results.

\begin{tabular}{lllll}
\hline Corrosion depth/mm & Simulation times & Failure probability & Reliability degree & Target reliability \\
\hline 1.886 & $10^{6}$ & $<0.00001$ & $>0.999999$ & 0.99 \\
3.772 & $10^{6}$ & $<0.00001$ & $>0.999999$ & 0.99 \\
5.658 & $10^{6}$ & $<0.00001$ & $>0.999999$ & 0.99 \\
7.544 & $10^{6}$ & 0.000259 & 0.999741 & 0.99 \\
9.430 & $10^{6}$ & 0.021267 & 0.978733 & 0.99 \\
\hline
\end{tabular}

\subsection{Reliability Calculation}

Due to the lack of corrosion defects of field test data, average length of corrosion defects is half of the diameter pipeline under variation coefficient of 0.1 ; defect depth for wall thickness of $10 \%, 20 \%, 30 \%$, $40 \%, 50 \%$ respectively under coefficient of variation of 0.1 . The diameter of $1,219 \mathrm{~mm}$ pipe is calculated by B31G method based on Monte-Carlo method X80. The calculation results (Table 4) show that when the corrosion depth is less than $30 \%$, the reliability of the wall thickness of the pipeline is far higher than 0.99. With the deepening of the corrosion depth, when the depth is greater than $40 \%$ of the pipe wall thickness, the reliability of the pipeline is less than the target reliability 0.99 . So when the corrosion depth is greater than $40 \%$ of the thickness of the pipe wall, the corresponding safety measures should be taken, such as replacing the new gas transmission pipeline or reducing the current operating pressure.

\subsection{Sensitivity Analysis}

For the gas pipeline with corrosion defects, the uncertain parameters of the pipeline include the outside diameter of the pipe, the thickness of the pipe wall, the yield strength and the pressure. The parameters of $100 \%, 250 \%, 150 \%, 200 \%, 300 \%$ times of standard deviation were analyzed to ensure the accuracy of the results, and the simulation times were $10^{6}$ times. The calculation results are shown in Fig. 2. The effect of these parameters on the pipeline reliability is not the same, which results in the greatest impact, is the pressure, yield strength, change of pipe diameter and pipe wall thickness standard deviation has little effect on the reliability. So the most sensitive parameter in the calculation of the reliability of the pipeline is the operating pressure, which should be controlled to the minimum degree of pressure fluctuations. 


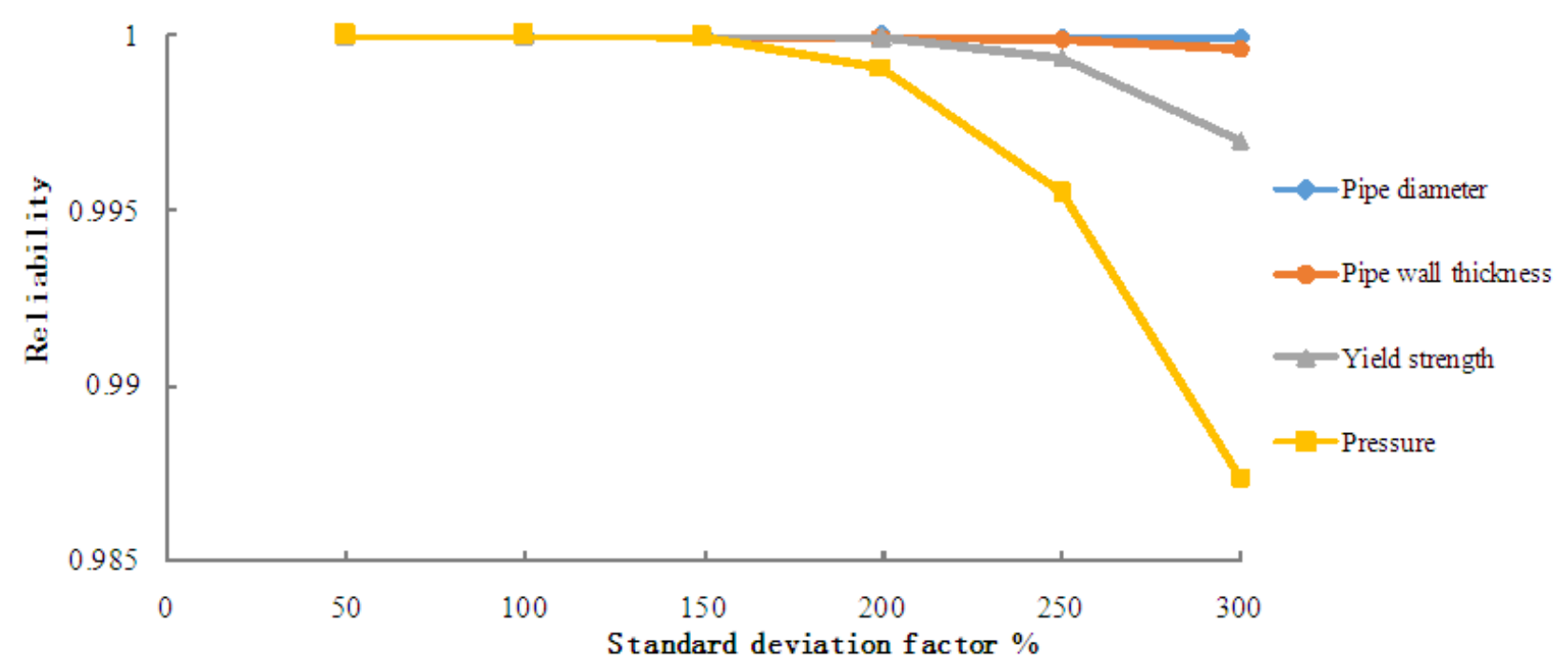

Fig. 2 Influence of parameter standard deviation on Reliability.

\section{Conclusions}

The X80 pipeline used in west east gas pipeline is considered as an example, and the reliability model of pipeline with corrosion defects is established based on the B31G standard. The parameters of uncertain gas transmission pipeline are brought into the limit state equation. The Monte Carlo method is to get the reliability of the results. Through the analysis, when the corrosion depth is greater than the pipe wall thickness of $40 \%$. The result of reliable degree calculation is less than the target reliability corresponding safety measures that should be taken, for example, replacing the pipe or reducing the current operating pressure. The sensitivity analysis of each parameter were carried out. The result shows that operating pressure is the most influential parameter to the reliability of the pipeline, so the fluctuation of the pressure should be reduced as much as possible during the pipeline operation.

\section{Reference}

[1] Liu, Y.-S., Wang W. and Feng Z.-Z. et al. 2008. "Analysis on Residual Strength and Reliability of Corroded Pipeline.” Intensity and Environment 35 (3):
$52-7$.

[2] Shuai, J. 2003. "Prediction of Remaining Life of Corroded Pipeline.” Journal of Petroleum University: Natural Science Edition 27 (4): 91-3.

[3] Zhang, G.-L., Zhao, X.-W. and Luo, J.-H. et al. 2012. "Study on Probabilistic Evaluation Method of Corrosion Defect Pipelines Based on Different Evaluation Criteria.” China Journal of safety science 22 (9): 57.

[4] Ahammed, M. 1998. "Probabilistic Estimation of Remaining Life of a Pipeline in the Presence of Active Corrosion Defects." International Journal of Pressure Vessels and Piping 7 (54): 321- 9.

[5] American Society of Mechanical Engineers. ANSI/ASME B31G-2009. 2009. "Manual for Determining the Remaining Strength of Corroded Pipeline.” New York: ASME B31 Committee.

[6] Det Norske Veritas. 1999. DNV-RP-F101 1999. "Recommended Practicefor Corroded Pipelines." Oslo: Det Norske Veritas.

[7] API 579-2000. 2000. "Recommended Practice for Fitness for Service.” ISSUE6.Washington DC: American Petroleum Institute.

[8] Zhang, H., Gu, X.-T. and Zhao, L.-H. 2011. "Study on Design Coefficient of Oil and Gas Pipeline Based on Reliability.” Welded Pipe and Tube 34 (4): 58-62.

[9] Chen, C., Xi, Z.-D. and Zhu, H.-W. 2013. "Reliability of Gas Pipeline Structure Containing Defects a New Evaluation Method for Oil and Gas Storage and Transportation.” Oil \& Gas Storage and Transportation 32 (6): 590-3. 